\title{
TRADITIONAL FOOD PRODUCTS VS. GLOBAL ECONOMY: CONSUMER PESPECTIVE
}

\author{
Ružica Lončarić ${ }^{1}$, Tihana Sudarić ${ }^{2}$, Krunoslav Zmaić ${ }^{3}$ \\ *Corresponding author E-mail: rloncaric@fazos.hr
}

A R T I C L E I N F O
Original Article
Received: 22 March 2021
Accepted: 28 May 2021
doi:10.5937/ekoPolj2102389L
UDC
338.439.02:339.9]:659.113.25

Keywords:

attitude, consumers, east

Croatia, preferences, traditional food products

JEL: D12, Q13

\begin{abstract}
A B S T R A C T
The Osijek-Baranya County at the east part of Croatia, generally is known as lowland region in whose economy agriculture and food industry are of great importance. Eastern Croatia abounds in various traditional products, mainly based on smoked pork. The goal of this paper is to identify consumers' attitudes and behavior towards east Croatia traditional food products (TFP). Furthermore, the model for market power evaluation of each east Croatia TFP is created according to consumers" preferences and attitudes results. The research was performed in Osijek-Baranya County in spring 2019. The sample was consisted of 500 randomly chosen respondents older than 18 via self-fulfilled questionnaire survey. In paper is used descriptive, parametric and non-parametric statistics. People in East Croatia have a positive attitude to TFP of their region. Survey results related to supply, quality, demand and price willingness are used to modelling coefficient for East Croatia TFP commercialization. This coefficient can help producers and policy makers to decide easier about the most perspective production from market point of view. According to the survey results, production of kulen, cottage cheese, ham, honey and sausages are the most promising.
\end{abstract}

(C) 2021 EA. All rights reserved.

1 Ružica Lončarić, Ph.D., Full Professor, Faculty of Agrobiotechnical Sciences Osijek, Department for Bioeconomics and Rural Development, Vladimira Preloga 1, HR-31000 Osijek, Croatia, Phone: +385 31554 871, E-mail: rloncaric@fazos.hr, ORCID ID (https:// orcid.org/0000-0001-8718-8103)

2 Tihana Sudarić, Ph.D., Associate Prefessor, Faculty of Agrobiotechnical Sciences Osijek, Department for Bioeconomics and Rural Development, Vladimira Preloga 1, HR-31000 Osijek, Croatia, Phone: +385 31554 841, E-mail: tsudaric@fazos.hr, ORCID ID (https:// orcid.org/0000-0001-8205-1765)

3 Krunoslav Zmaić, Ph.D., Full Professor, Faculty of Agrobiotechnical Sciences Osijek, Department for Bioeconomics and Rural Development, Vladimira Preloga 1, HR-31000 Osijek, Croatia, Phone: +385 31554 801, E-mail: kzmaic@fazos.hr, ORCID ID (https:// orcid.org/0000-0001-7860-0098) 


\section{Introduction}

Traditional food products (TFP) are an important part of European culture, identity, and heritage (Guerrero et al., 2009). Within the European food market, traditional food products represent a growing segment. A traditional food product is a product frequently consumed or associated to specific celebrations and/or seasons, transmitted from one generation to another, made in a specific way according to gastronomic heritage, naturally processed, and distinguished and known because of its sensory properties and associated to a certain local area, region or country (Vanhonacker et al., 2010 b). Traditional foods reflect cultural inheritance and have left their imprints on the respective dietary patterns, despite the fact that contemporary lifestyles do not encourage their preservation in our daily lives and customs (Trichopoulou et al., 2007). Slimani et al. (2002) reported that despite the fact that we are living in a world of globalization, different dietary patterns between countries do exist, although they are narrowing as reported by Trichopoulos \& Lagiou (2004). These differences should be welcomed as they represent an acknowledgment of our traditions. In most cases, the variety in dietary habits derives from the fact that inhabitants had to adapt to climatic conditions. In order to produce more food for themselves, people have developed methods of farming, processing and preserving suitable foods. As time passed and societies developed, the dietary choices become integral part of the culture and nutritional choices, including traditional foods as parts of their collective identity as also indicated by Behar (1976). Guerrero et al. (2010) emphasizes that Southern European regions tended to associate the concept of "Traditional" more frequently with broad concepts such as heritage, culture or history. Central and North European regions tended to focus mainly on practical issues such as convenience, health or appropriateness. However, the time criterion is recently connected with traditional food. So, Sajdakowska \& Zakowska - Biemans (2009) indicates that the European Commission use the term "traditional" in relation to those food products, which have been present in the EC markets for a particular period during which they were handed down from generation to generation. At the same time, it is suggested that such a time period should correspond with a period ascribed to one generation and last at least 25 years. Furthermore, traditional food is characterized as the food conformable with the practices established or having specifications formulated before World War II.

Traditional food is a food of a specific feature or features, which distinguish it clearly from other similar products of the same category in terms of the use of "traditional ingredients" (raw materials or primary products) or "traditional composition" or "traditional type of production and/or processing method" (Trichopoulou et al., 2007)

According to Trichopoulou et al. (2007) it was necessary to define the term traditional because it is a precondition to highlight food that is considered traditional on food composition declarations. Two directives prescribe topic local/traditional food traded in EU: Council Regulation No 2081/92 (Commission of the European Communities, 1992a) regarding "protection of geographical indications and designations of origin for agricultural products and foodstuffs". Later (2006) this directive was substituted 
by Council Regulation No 510/06 "On the protection of geographical indications and designations of origin for agricultural products and foodstuffs" (Commission of the European Communities, 2006a). Also, in 1992 was prescribed Council Regulation No 2082/92 "On Certificates of Specific Character for agricultural products and foodstuffs" (Commission of the European Communities, 1992b), while this directive was substituted by Council Regulation No 509/06 of 20 March 2006 "On agricultural products and foodstuffs as traditional specialties guaranteed" (Commission of the European Communities, 2006b).

Furthermore, the same authors (Trichopoulou et al., 2007) claim that these directives have a goal to ensure a simple system to protect the names of food on traditional of geographical base. The directives about "PDO - Protected Designation of Origin" and "PGI - Protected Geographical Indication" has been successfully applied resulted in registration of many European foods. On the other hand, the third designation - TSG or Traditional Specialty Guaranteed is not implemented so much, and very few foods is registered by TSG label. The reason can be regulation 2082/92 that lacking in distinction of definition of the term "traditional", so this resulting in a disability to ensure the exclusive registration of traditional foods, especially applies to composite foods.

These quality schemes are developed to protect producers and consumers from inferior, copycat goods in order to only approved consortium members can be users of a registered name (Balogh et al., 2016). According to Giovannucci et al. (2009, cited in Vandecandelaere et al., 2021) the trade value of food with geographical labels exceeds 50 billion of USD. Many of these products are very famous, such as tea Darjeeling tea or cheese Parmigiano-Reggiano. Many of that goods earn their status based on geographical indication registration.

Vanhonacker et al. (2010a) researched the characteristics of European TFP consumers regarding their socio-demographics characteristics, opinions, life-style as well as behavior. They also conclude that consumption and importance of traditional food in the EU south is more pronounced than in EU north. They also concluded that TFP consumer's characteristics are: middle-aged to elderly, conscious about health, ethnocentric, food connoisseurs, who know food and love to cook

On the other side, EU farmers confront worsening terms of trade and declining real incomes, and generally remain dependent on direct payments and other subsidies for survival (European Commission, 2014). Rural areas in the NMS are more dependent on agriculture as a source of income and employment, with opportunities for gainful employment in the non-farm rural economy relatively scarce (Davidova et al., 2013). Gellynck \& Kuhne (2008) explore innovations implemented by SMEs in the traditional food sector and how chain network members are contributing to this process. Their results show that the members of traditional food chain networks focus mainly on product innovation and least on organizational innovation. Collaboration between the chain network members is an important factor for enhancing the innovation competence of the firms. However, the collaboration intensity depends on the position of the members 
in the chain network. However, the ability of TFPs to contribute to improved farm incomes, without recourse to subsidies, depends on whether consumers are willing to pay a premium for them compared to cheaper alternatives. In other words, with TFPs not receiving any direct, supplementary subsidies, additional value added has to come on the demand side but the willingness of consumers to pay for such goods, and specific attributes that may be attached to them, remains unclear (Balogh et al., 2016). Benedek \& Balázs (2016) paper draws attention to the importance of the national level in the local development planning, which is needed to harmonize national development processes with wider European initiatives.

Gellynck et al. (2012) analyzed the market orientation of SMEs ( $\mathrm{N}=150)$ by investigating their marketing management capabilities in the traditional food sector. Most of the SMEs in the sample lack marketing management capabilities, even if a considerable proportion of the firms considered report good marketing capabilities that lead to a market orientation. The weakest step of market orientation is the dissemination of generated intelligence. Indeed, SMEs lack marketing organizational activities, namely in planning and implementation of marketing strategy.

Croatian traditional products for a long time have been neglected because of the unfavorable legislative framework and lack of initiative. Over the last few years, the offer of these products as well as the number of involved manufacturers has been increasing due to the Government and Local Government Initiative, which have stimulated projects to revive TP production and supply. Croatia is tourist country with pure environment and beautiful nature as well as country abundant with wealth of traditional local products. But, Croatia hasn't sufficient supply of such products to satisfy the domestic food and touristic markets. The reasons for such situation is in the fact that production technology of the majority of domestic food products reply on a traditional technology or recipe of a small number of family farms in the Croatian regions. In addition, there is less interest in TP in restaurants due to higher TP prices, while foreign consumers are hardly familiar with these products because of inadequate promotion of Croatian gastronomic offer (Renko \& Bučar, 2014).

Nevertheless, a small number of traditional products with its quality and originality, based on traditional technology, found the way to many consumers and acquired characteristics of superior specialties in Slavonia cuisine, Mediterranean and continental cuisine. In addition, the prices of these products and their market position have become one of the major driver trends of increasing family farms' interest for the production of local products in all Croatian regions. Traditional products can be classified into three groups: primary agricultural products, traditional (processed) products and traditional dishes. In this paper we mostly discuss about traditional processed products of East Croatia, because those traditional products are the most famous and known in this region.

The sample was consisted of respondents from Osijek-Baranya on east of Croatia. Osijek-Baranja County is known as lowland region where agriculture and related industries are the most important for economy. 
The goal of this paper is to identify consumers' attitudes and their behavior towards east Croatia traditional food products (TFP). Furthermore, the model for market power evaluation of each east Croatia TFP is created according to survey results. The model is used to evaluate market potential of east Croatia TFP. This model can be used for other regions/products as well.

\section{Materials and methods}

The research was performed in spring 2019 and represents a repeated survey from 2012 (Zmaic et al., 2014) on the sample of 500 randomly chosen respondents from OsijekBaranya County older than 18 via self-fulfilled questionnaire survey. The questionnaire contained questions about: familiarity and preferences regarding traditional food products, the frequency, place and occasion of purchase and consumption of traditional East Croatia food products, quality evaluating of the most prominent TFP of East Croatia, supply satisfaction, price willingness and the overall importance of TFP for local community and development.

Statistical analysis was performed using SAS System for Windows. Descriptive statistics (frequencies, cross-tabulations) and non-parametric tests (Mann-Whitney for two-independent samples) are used in order to identify the statistical significance of demographic variables on overall opinion of importance of TFP. The level of significance is set at $\mathrm{p}<0.05$. Nominal scale data were analyzed by two sample chisquare test. This test is used for examination of the independence of two variables or factors, randomness and goodness-to-fit. Analysis of variance (ANOVA) and Tukey test with a level of confidence of $95 \%$ were performed $(p<0,05)$ for the Likert scale data: opinions regarding supply from 1 to $3(1=$ oversupply, $2=$ sufficient supply, $3=$ insufficient supply), quality from 1 to 5 (1=lowest rating, $5=$ highest rating), buying frequency of TFP from 1 to 4 ( $1=$ never, $2=$ rarely, $3=$ sometimes, $4=$ often $)$ and willingness to pay (\%). In order to show statistical differences according to mentioned variables of TFP, the letter notification is used. Between values containing the same letter there is no statistical difference (for example a and $a b$ ). Values containing all different letters show differences which is statistically significant (for example a and bc). Variable value letter notification is ascending (for example $\mathrm{a}$ is the lowest value, $\mathrm{b}$ is higher, etc.).

Some results derived from this research we used to rank some TFP of East Croatia according to commercialization potential/power (supply, demand, quality and price willingness). For each TFP is taken into account average value of survey regarding supply (1-3), TFP quality (1-5), demand (1-4) and the average value for willingness to pay $(\%)$ divided by 10 .

TFP coefficient for commercialization $=\mathrm{S}+\mathrm{Q}+\mathrm{D}+\mathrm{PW} / 10$

where: $\mathrm{S}=$ supply, $\mathrm{Q}=$ quality, $\mathrm{D}=$ demand, $\mathrm{PW}=$ price willingness. This model allows to rank TFP taking into account consumer opinion regarding TFP importance. 


\section{Results and discussion}

Croatian TFP compete for other food products on the global market because of its technological, nutritional and organoleptic specificities, quality and specialty. The system of registration and protection of names of agricultural and foodstuffs with the designation of origin or geographical indication and the designation of traditional reputation is regulated by the Law on Authentication, Geographical Indications and Trademarks of Agricultural and Food Products (National Newspaper 2012) is in compliance with EU regulation. Later is adopted Regulation on protected certificates of origin, geographical indications and guaranteed traditional specialties of agricultural and food products (National Newspaper, 2015). These regulations govern the area of product registration at the national level. By joining the European Union, Croatia get one year to protect its products according to the European Union legislation. Labels in EU Member States are awarded on the basis of Council Regulation (Commission of the European Communities, 2006a and 2012). Since 2015 when first Croatian product is registered, now there is 60 endogenous products in European DOOR database (Database of Origin and Registration). DOOR database divide products according to product type: food, wine, spirit drinks and aromatized wine. From total number, for 55 Croatian products registration is finalized (registered), 1 product is in objection stage (published) and for 10 products documentation is submitted and registration process just follow (applied). The most dominant registration certificate for Croatian traditional products is PDO (Protected designation of origin) - 31, followed by PGI (Protected geographical indication) - 17. For GI (Geografical indication), there is 7 products, and that certification is related only to spirit drinks and aromatized wine. There is no one Croatian product in TSG group (Traditional Specialties guaranteed). Among 55 fully registered products, there is only 7 from East Croatia region where the research was conducted - Slavonska kobasica (Slavonian sausage), Slavonski med (Slavonian honey), Slavonski kulen/kulin (Slavonian kulen) and Baranjski kulen (Baranya kulen), wine Istočna kontinentalna Hrvatska (East Continental Croatia), wine Slavonija (Slavonya) and spirit drink Slavonska šljivovica (Slavonian slivovica). Eastern Croatia has many traditional food products, but the most important are TFP made from smoked pig meat (kulen, smoked Slavonian ham, sausages, smoked bacon, greaves, svargl), Slavonia brandy-rakija, cottage cheese and honey (Zmaić et al., 2014). Most of the population, especially in rural areas produce these products themselves for their own needs. Croatian traditional products have been forgotten for many years by the agricultural policies, agricultural experts and science. Unfavorable legal framework and lack of incentives additionally hampered the development of TFP production and sales. So, the economic benefits of these products were actually very small. The last 10 years, the supply of TFP and a number of TFP producers increased. Government and the local communities have prompted increasing number of projects to revive production and encourage sales of TFP. One of the most important initiatives is the process of protecting geographical origin of agro-food products. However, it is still a pioneering work, with very small quantities and limited resources of distribution. 


\section{Sample description}

In a total sample of 500 respondents, a similar number of male and female respondents participated. In terms of age structure, young respondents up to the age of 35 , participated the most $(55.2 \%)$. The educational structure of the respondents consisted mostly of less educated respondents (high school and lower). In the sample dominated urban population with an average family size of slightly less than 4 members, and an average income of around $€ 900$ (Table 1.).

Table 1. Socio-demographic characteristics of respondents

\begin{tabular}{|c|c|c|c|c|}
\hline & & $\mathbf{N}$ & Valid N & $\%$ \\
\hline \multirow{2}{*}{ Gender } & Male & 265 & \multirow{2}{*}{500} & 53.6 \\
\hline & Female & 231 & & 46.4 \\
\hline \multirow{5}{*}{ Age } & $15-25$ & 199 & \multirow{5}{*}{500} & 39.8 \\
\hline & $26-35$ & 76 & & 15.2 \\
\hline & $36-45$ & 74 & & 14.8 \\
\hline & $46-55$ & 95 & & 19.0 \\
\hline & $>55$ & 56 & & 11.2 \\
\hline \multirow{3}{*}{ Education } & High school or less & 323 & \multirow{3}{*}{493} & 65.5 \\
\hline & College & 117 & & 23.7 \\
\hline & Faculty & 53 & & 10,8 \\
\hline Family size (average) & & & 497 & 3.8 persons \\
\hline \multirow{2}{*}{ Residence } & Rural & 169 & \multirow{2}{*}{496} & 34.1 \\
\hline & Urban & 327 & & 65.9 \\
\hline Monthly income (average) & & & 450 & $6689.5 \mathrm{HRK}^{*}$ \\
\hline
\end{tabular}

Source: own research

* Croatian kuna (HRK); 1 EUR = 7,40 HRK (https://www.hnb.hr/, 14.6.2019.)

\section{Traditional vs. modern agricultural products}

Among the first questions in the survey, was the question regarding consumers' preferences for either conventional, either traditional agricultural products. This question was set as an introductory question with the aim of seeing the initial preference for traditional in relation to modern agriculture products. About half of respondents prefer traditional agriculture products $(54,3 \%), 37,6 \%$ are irrelevant and only 7,3\% of respondents prefer conventional, modern agriculture products. Also, we try to see is there some differences between subjects regarding their demographic characteristics (gender, education etc.). A chi-square analysis was performed to examine a possible significant association between the gender and preference toward different types of agricultural products, but significant association was not observed, $\chi 2(2, \mathrm{~N}=489)=$ $0.56, \mathrm{p}=0.75$. The similar situation was regarding age and level of education. But when respondents were divided according to income group, and combined with different other demographic characteristic, there is some associations between the lowest income group $(<400 €)$ and level of education where respondents are mostly irrelevant either traditional or conventional agricultural products $(60 \%)$ of they even prefer modern 
agricultural products $(40 \%)-\chi 2(8, \mathrm{~N}=5)=25.546, \mathrm{p}=0.001$. The similar situation is observed between this income group and level of education where respondents with college diploma are more irrelevant than any other group of respondents $\chi^{2}(4, \mathrm{~N}=4)$ $=10,074, p=0.39$. Probably their answers are different because of the small number of respondents in those groups.

\section{Attitudes of respondents towards TFP}

According to the similar research from 2012 (Loncaric et al., 2015) respondents have generally positive attitude towards TFP. The advantages of TFP they evaluated 4.37 in average (on Likert scale from 1 to 5) while the disadvantages they rated 3.57. According to them, the most important advantages of TFP are better taste, originality and quality, while high cost and not sufficiently recognizable TFP labeling are the main disadvantages. The least significant disadvantage of TFP is the lack of supply, what is connected to production of TFP on many farms in rural areas, but also with an emphasized initiative of the Government and local administration what resulted in positive effects in the food supply. These results were expected, since East Croatia TFP is well known to their respondents in terms of recipe, technology and taste. Furthermore, results indicated that consumers consider TFP as important for the benefit of the wider community, particularly on its role for conservation of culture and heritage, as well as necessity for better respect and status of TFP by society. In this context Florek \& Gazda (2021) stated that investment in promotional and marketing activities for supporting TFP affect wider economic development of region and if community participate in TFP development it leads to more sustainable economic development too. TFP importance can be enhanced by actors in local community and strengthened by marketing activities.

\section{Familiarity and preferences towards TFP}

Consumers' associations towards traditional products of East Croatia were primarily related to kulen, sausages, greaves, ham, cottage cheese and rakija, slightly less on the bacon, honey, jam and svargl. These answers respondents should fill in by themselves (Figure 1). 
Figure 1. TFP according to consumer opinion - filled in answers (\%)

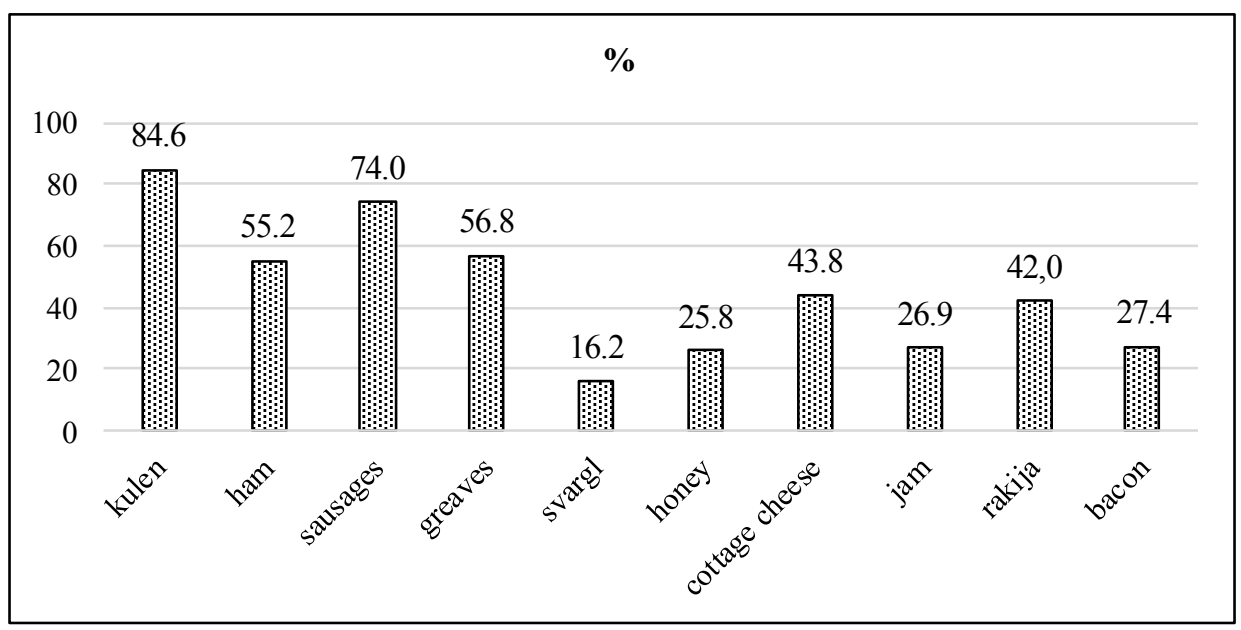

Another issue was related to traditional products that consumers actually buy and consume (Figure 2). In this case answers were already offered. Answers regarding TFP on both questions (open question and offered TFP) match with slightly difference regarding bacon suggested by the consumers, because bacon was not mentioned in offered answer as TFP.

Figure 2. TFP according to consumer opinion - offered answers (\%)

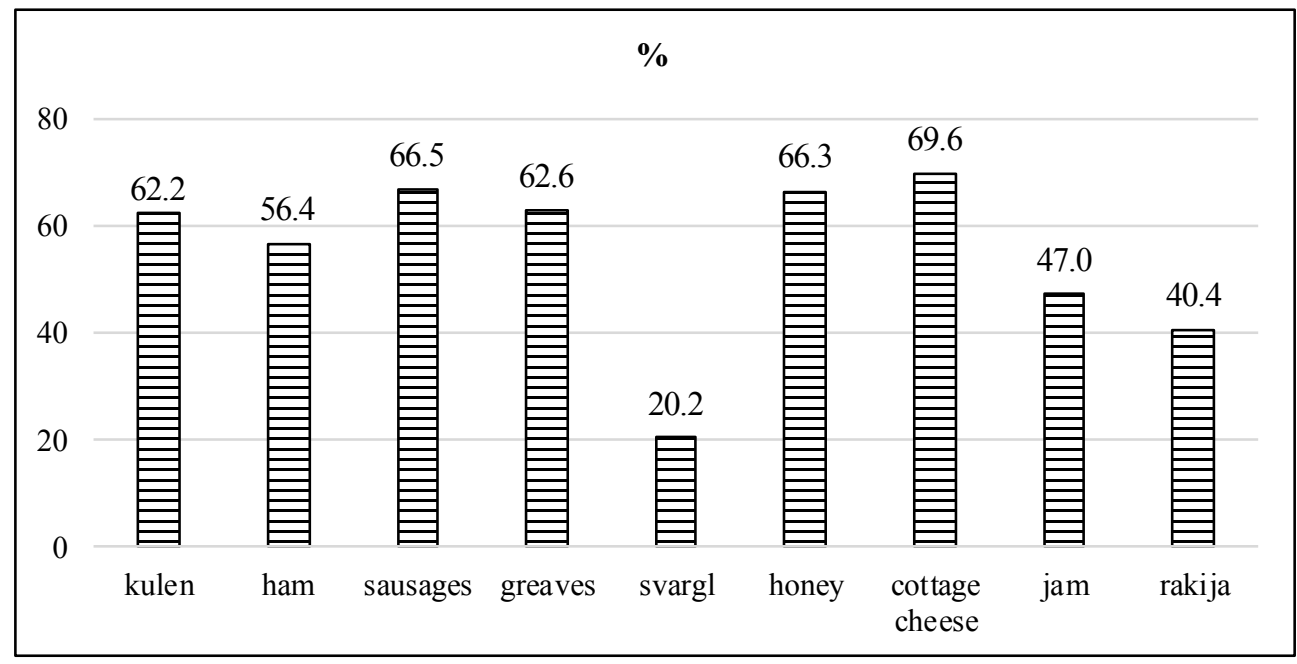

We can notice different frequency of answers compared to the previous question, in which the greatest share was related to the cottage cheese and honey. Honey and cheese present exception. East Croatia is mostly recognized for crop production, while livestock production is not so present to that extent (milk and cattle-meat industry), so it is not surprising that consumers buy those products more, because they do not produce it. 


\section{TFP purchase place and consuming \& buying occasions}

Currently, the respondents mostly buy TFP on green markets $(34,7 \%)$ and directly from producers $(32.0 \%)$. TFP are rarely purchased at supermarkets $(16,4 \%)$, specialized shops $(9.3 \%)$ and on agro-tourism farms $(7.7 \%)$. Chi-square analysis obtained a significant association between monthly income and favorite current purchase place of TFP $\chi^{2}(16, \mathrm{~N}=330)=34.33, \mathrm{p}=0.005$. According to that, respondents with higher family income $(>1600 €)$ prefer more purchasing TFP directly from producers. When it comes to the buying occasions, consumers buy and consumer TFP mostly at home as regular meal $(69 \%)$, on celebrations (47\%) and during holidays (38\%). TFP is less frequently used as a gift (12\%) or as part of a restaurant offer $(6 \%)$. The most preferred purchase place for consumers is direct purchase at TFP producer's farms $(41.4 \%)$, less on city greenmarkets $(20.8 \%)$, while significant association has been observed between the level of education and the most suitable TFP purchase place, $\chi 2(8, \mathrm{~N}=394)=$ 19.09 , because $\mathrm{p}=0.014$. This is in line with Balogh, $2016 \&$ Benedek 2016. Among the respondents with the lowest education, monthly income significantly affects the choice of the most suitable places of purchase TFP, $\chi 2(16, \mathrm{~N}=237)=32.82, \mathrm{p}=0.008$, since they prefer purchase directly from farmers more than other consumers.

\section{Market power of East Croatia TFP}

In order to create model for evaluating market power of East Croatia TFP, we calculate results regarding supply, quality, buying frequency (demand) as well as willingness to pay. In order to evaluate results for supply, the highest rating was given to products with lowest supply (3), for the TFP product with sufficient supply was given grade 2, and the lowest rating was given to products considering oversupply (1). The reason for such grading is that products with lowest supply have great potential for increasing production, or they have higher resorption power. According to results represented in Figure 3, the lowest grade in terms of supply was given to rakija (1.91) and sausages (1.92). The reason for such results probably is that most or population in rural areas make those products for their own needs. Statistical analysis showed that ratings for rakija and sausage are statistically different from rating products that have the highest ratings in terms of supply $\left(\mathrm{P}<0.05^{*}\right)$, such as kulen (2.13), svargl $(2,30)$ and graves $(2.30)$. 
Figure 3. TFP supply ( $1=$ oversupply, $2=$ sufficient supply, $3=$ insufficient supply)

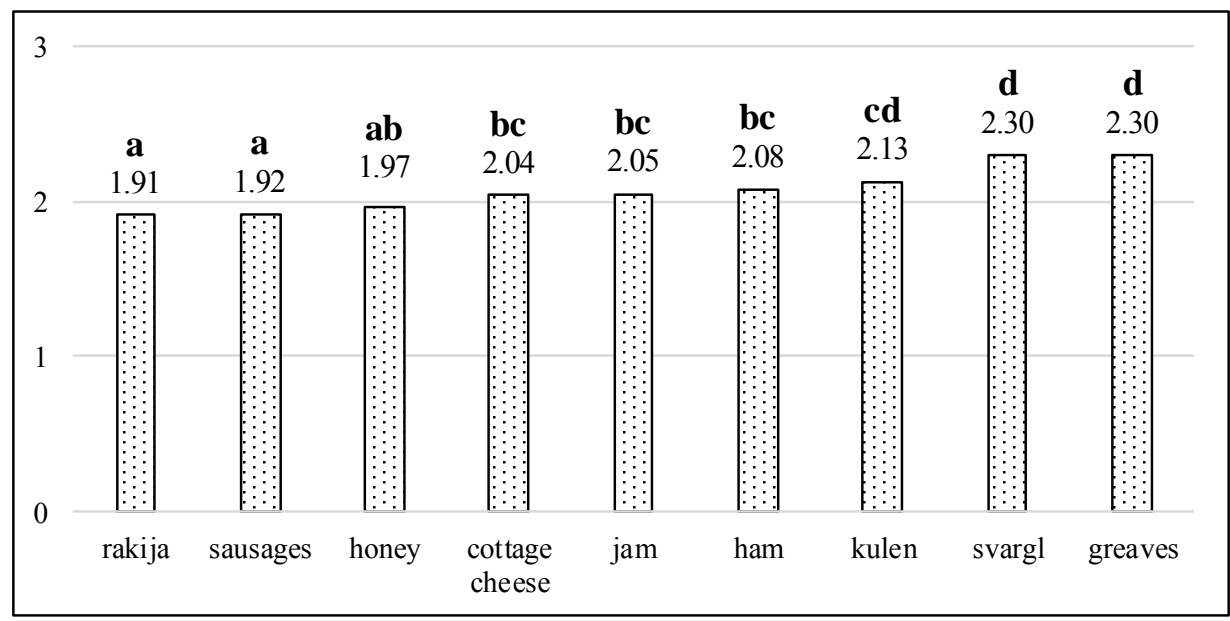

* Scale data (1-3) were analyzed using one-way analysis of variance (ANOVA and Tukey HSD test). Values containing same letter have not difference statistically significant, values with the different letter have difference statistically significant $(\mathrm{p}<0,05)$

Product quality is a growingly and significant aspect for the traditional food producers. In fact, insisting on the quality has arising as a solid opportunity of growth on international markets. The use of quality related to the place of origin to differentiate a product can be understood as particular brand strategy (van Ittersummet al., 2003). Traditional foods, apart from being vehicles of our culture, may also possess health qualities, since tradition rarely honors foods which are not palatable and healthy (Trichopoulos \& Lagiou, 2004). Espejel et al. (2007) found a direct effect of perceived quality of traditional food on satisfaction, loyalty and purchasing intention. In our research respondents rated TFP quality high, too.

Regarding quality of east Slavonia TFP (rated on Likert scale from 1 to 5), respondents consider svargl and greaves as products with lowest quality, probably due to the high fat content. Consumers consider honey, sausages, cheese, ham and kulen as products with highest quality. Those products ratings scale was from 4,2 to 4,6. Statistically significant differences between products when it comes to quality criteria were confirmed on 0.05 level $\left(\mathrm{P}<0,05^{*}\right)$. The data are shown in Figure 4. 
Figure 4. TFP quality evaluation according to consumers (Likert scale 1-5; 1=lowest rating, $5=$ highest rating)

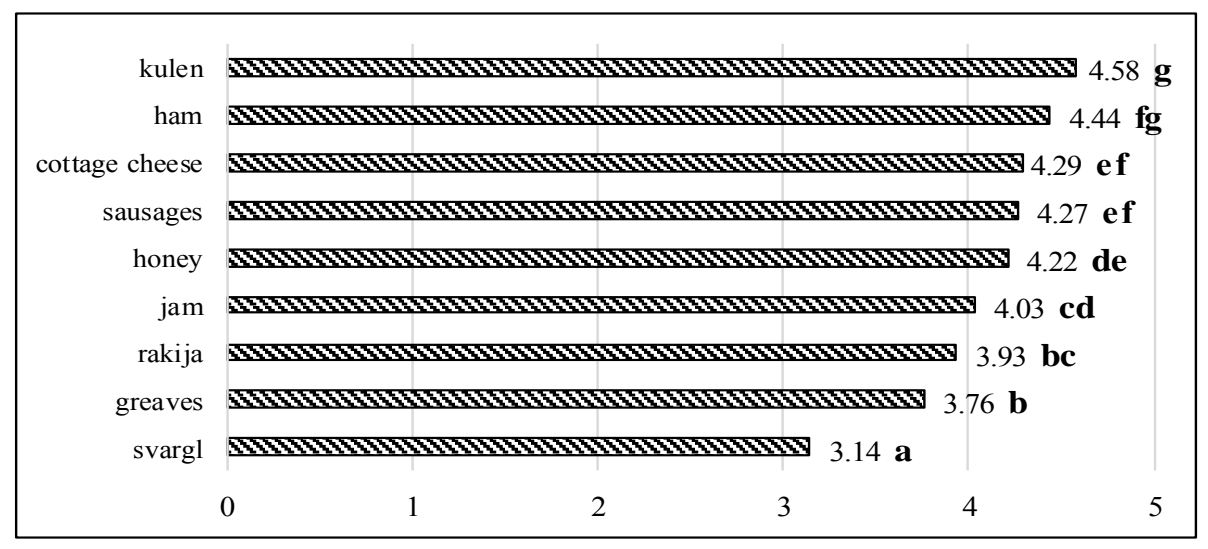

*Likert scale data (1-5) were analyzed using one-way analysis of variance (ANOVA and Tukey HSD test). Values containing same letter have not difference statistically significant, values with the different letter have difference statistically significant $(p<0,05)$

Respondents buy cottage cheese and honey the most frequently. It is expected, because East Croatia is not known in milk and honey production. All other products many people in this region produce by themselves. Consumers' willingness to pay is in correlation with TFP quality. Respondents stated they are willing to pay more than $25 \%$ for kulen, ham, cheese, honey and sausages as opposed to svargl and greaves (13.7 and 17.5\% respectively). There is statistically confirmed differences between greaves and svargl (lowest rank) and kulen (highest rank). Table 2. shows purchase frequency of selected products and willingness to pay.

Table 2. Consumers' buying frequency of TFP ( $1=$ never, $2=$ rarely, $3=$ sometimes, $4=$ often $)$ and willingness to pay higher price for traditional products $(\%)$

\begin{tabular}{|c|c|c|c|c|}
\hline & \multicolumn{2}{|c|}{ TFP buying frequency } & \multicolumn{2}{c|}{ Willingness to pay } \\
\hline & Average 1-4 & $\begin{array}{c}\text { ANOVA and } \\
\text { Tukey HSD* }\end{array}$ & Average (\%) & $\begin{array}{c}\text { ANOVA and } \\
\text { Tukey HSD* }\end{array}$ \\
\hline svargl & 1.79 & $\mathrm{a}$ & 13.7 & $\mathrm{a}$ \\
\hline greaves & 1.90 & $\mathrm{a}$ & 17.5 & $\mathrm{~b}$ \\
\hline rakija & 2.13 & $\mathrm{~b}$ & 25.1 & $\mathrm{~cd}$ \\
\hline kulen & 2.42 & $\mathrm{c}$ & 30.0 & $\mathrm{~d}$ \\
\hline jam & 2.46 & $\mathrm{c}$ & 23.7 & $\mathrm{c}$ \\
\hline ham & 2.46 & $\mathrm{~cd}$ & 27.7 & $\mathrm{c}$ \\
\hline sausages & 2.68 & $\mathrm{~d}$ & 26.0 & $\mathrm{~cd}$ \\
\hline honey & 2.93 & $\mathrm{e}$ & 26.3 & $\mathrm{~cd}$ \\
\hline cottage cheese & 3.02 & $\mathrm{e}$ & 27.5 & $\mathrm{~cd}$ \\
\hline
\end{tabular}

** Scale data (1-4) and data (\%) were analyzed using one-way analysis of variance (ANOVA and Tukey HSD test). Values containing same letter have not difference statistically significant, values with the different letter have difference statistically significant $(p<0.05)$ 
De Roest \& Menghi (2000) differ the position of the small niche market traditional products and traditional products marketed on national or international markets related to price making. They stated that the small niche market products operate in many cases on almost monopoly markets, where producers, because of the exclusivity of the product, can raise their prices relative to the price of competing product without losing sales. They face what is essentially a downward sloping demand curve. The products marketed on (inter-) national markets on the contrary, at times have to face fierce competition from industrially produced substitutes. They are thus indirectly subjected to the same price-cost squeeze as their industrial substitutes. East Slavonia traditional products certainly belong to the first group.

When all of these results are summed up, we calculated coefficient for commercialization of each TFP (Table 3).

Table 3. Evaluation of market power (commercialization coefficient) for east Croatia TFP

\begin{tabular}{|l|c|c|c|c|c|c|}
\hline & Supply & Quality & Demand & Price & $\begin{array}{c}\text { Commercialization } \\
\text { coefficient }\end{array}$ & Rank \\
\hline kulen & 2.13 & 4.55 & 2.42 & 3.00 & 12.13 & 1. \\
\hline ham & 2.08 & 4.44 & 2.48 & 2.77 & 11.77 & 3. \\
\hline sausages & 1.92 & 4.27 & 2.68 & 2,60 & 11.47 & 5. \\
\hline greaves & 2.30 & 3.76 & 1.90 & 1.75 & 9.72 & 8. \\
\hline svargl & 2.30 & 3.14 & 1.78 & 1.37 & 8.59 & 9. \\
\hline honey & 1.97 & 4.22 & 2.93 & 2.63 & 11.75 & 4. \\
\hline cottage cheese & 2.03 & 4.29 & 3.02 & 2.75 & 12.10 & 2. \\
\hline jam & 1.05 & 4.03 & 2.46 & 2.37 & 9.91 & 7. \\
\hline rakija & 1.91 & 3.93 & 2.13 & 2.51 & 10.47 & 6. \\
\hline
\end{tabular}

This coefficient can help producers to decide easier about the most perspective production from market point of view. Also, it can help policy makes to decide what production should be supported taking into account consumer perspective. According to this model, production of kulen, cottage cheese, ham, honey and sausages are the most promising TFP in Eastern Croatia.

Final question was to evaluate the importance of TFP for local economy. The average score (on scale from 1 to 5) was pretty high - 4.40. This is in line with Borowska, 2010 and Balogh, 2016 research. A Mann-Whitney test indicated that importance of traditional agricultural products was greater for the people who live in the city (Mean Rank=254.69) than for people living in villages (Mean Rank=230.70), $U=24562.0$, $\mathrm{p}=0.04$. It is expected because most people in rural region see these products as ordinary products because they produce it for their own needs.

\section{Conclusions}

People in East Croatia have a positive attitude to TFP of their region (4,40 on 1 to 5 Likert scale). East Croatia's TFP are very favored by its residents what is the reason that we didn't find many differences in statistical dependences of some demographic groups and their positive preferences towards TFP. It should be considered in TFP 
market preparing to increase consumers' confidence towards TFP. Croatia is a tourist country and as such it should nurture and promote domestic indigenous products in order to use this potential, both promotionally and financially. Commercialization coefficient ranked east Croatia TFP according to consumer's point of view on supply, demand, quality, buying frequency and willingness to pay. This coefficient can help producers to decide easier about the most perspective production from market point of view. According to the results, production of kulen, cottage cheese, ham, honey and sausages are the most promising. It also can be the guide for agricultural policy makers to give priority to some TFP when it comes to the process of protecting geographical indication of TFP.

\section{Conflict of interests}

The authors declare no conflict of interest.

\section{References}

1. Balogh, P., Békési, D., Gorton M., Popp, J., \& Lengyel, P. (2016). Consumer willingness to pay for traditional food products. Food Policy 61, 176-184. https:// doi.org/10.1016/j.foodpol.2016.03.005

2. Behar, M. (1976). European diets vs traditional foods. Food Policy, 1(5), 432-435. https://doi.org/10.1016/0306-9192(76)90088-9

3. Benedek, Z., \& Balázs, B. (2016). Current status and future prospect of local food production in Hungary: a spatial analysis. European Planning Studies, 1-18. https:// doi.org/10.1080/09654313.2015.1096325

4. Borowska, A. (2010). The role of traditional and regional food in rural development in Poland. Socialiniai tyrimai / Social Research. 2010, 1 (18), 40-52. Retrieved from: http:/yucita.org/uploads/yayinlar/diger/makale/The_Role_of_Traditional_and Regional_Food_Products_in_RuralDevelopment_in_Poland.pdf (February 1, 2021$)$

5. Commission of the European Communities (1992a). Council Regulation (EEC) No 2081/92 on the protection of geographical indications and designations of origin for agricultural products and foodstuffs. Official Journal, L208, 1-8. Retrieved from: https:/op.europa.eu/en/publication-detail/-/publication/7332311d-d47d-4d9b927e-d953fbe79685/language-en (February 1, 2021)

6. Commission of the European Communities (1992b). Council Regulation (EEC) No 2082/92 on certificates of specific character for agricultural products and foodstuffs. Official Journal, L208, 9-14. Retrieved from: https://op.europa.eu/en/publicationdetail/-/publication/a109261e-f10f-4710-a609-5d4a0a282252 (February 1, 2021)

7. Commission of the European Communities (2006a). Council Regulation (EC) No $510 / 2006$ on the protection of geographical indications and designations of origin for agricultural products and foodstuffs. Official Journal of the European Union L 93/12. Retrieved from: https:/eur-lex.europa.eu/eli/reg/2006/510/oj (January 19. 2021) 
8. Commission of the European Communities (2006b). Council Regulation (EC) No 509/2006 on agricultural products and foodstuffs as traditional specialties guaranteed. Official Journal of the European Union, L93, 1-11. Retrieved from: https://eur-lex.europa.eu/legal-content/EN/TXT/PDF/?uri=CELEX:32006R0509 (January 20, 2021)

9. Commission of the European Communities (2012). Council Regulation (EC) No 1151/2012 of the European Parliament and of the Council on quality schemes for agricultural products and foodstuffs. Official Journal of the European Union, L343/1, 1-28. Retrieved from: https:/eur-lex.europa.eu/LexUriServ/LexUriServ. do?uri=OJ:L:2012:343:0001:0029:en:PDF (January 15, 2021)

10. Commission of the European Communities (2014): EU Agricultural Market and Income 2014 - 2024 Report. DG Agriculture and Rural Development, Brussels. Retrieved from: https:/ec.europa.eu/info/sites/info/files/food-farming-fisheries/ farming/documents/agricultural-outlook-report-2014_en.pdf (December 4, 2020)

11. Davidova, S., Bailey, A., Dwyer, J., Erjavec, E., Gorton, M., \& Thomson, K. (2013). Semi-Subsistence Farming - Value and Directions of Development Policy Department B: Structural and Cohesion Policies. European Parliament, Brussels. Retrieved from: https://www.europarl.europa.eu/RegData/etudes/etudes/ join/2013/495861/IPOL-AGRI_ET(2013)495861_EN.pdf (November 21, 2020)

12. De Roest, K., \& Menghi, A. (2000). Reconsidering 'Traditional' Food: The Case of Parmigiano Reggiano Cheese. Sociologia Ruralis, 40(4), 439-451. https://doi. org/10.1111/1467-9523.00159

13. Espejel, J., Fandos, C., \& Flavian, C. (2007). The role of intrinsic and extrinsic quality attributes on consumer behaviour for traditional food products, Managing Service Quality, 17 (6), 681-70. https://doi.org/10.1108/09604520710835000

14. Florek, M., \& Gazda, J. (2021). Traditional Food Products-Between Place Marketing, Economic Importance and Sustainable Development. Sustainability, 13, 1-14. https://doi.org/10.3390/su13031277

15. Gellynck, V., Banterle, A., Kühne, B., Carraresi, L., \& Stanieri, S. (2012). Market orientation and marketing management of traditional food producers in the EU. British Food Journal 114(4), 481-499. https://doi.org/10.1108/00070701211219513

16. Gellynck, X., \& Kühne, B. (2008). Innovation and collaboration in traditional food chain networks. Journal on Chain and Network Science, 8(2), 121-129. https://doi. org/10.3920/JCNS2008.x094

17. Giovannucci, D., Josling, T., Kerr, W.A., O`Connor, B., \& Yeung, M.T. (2009). Guide to Geographical Indications - Linking Products and Their Origins. Geneva: International Trade Centre. Retrieved form: https://www.researchgate. net/publication/260001725_Guide_to_Geographical_Indications_-_Linking_ Products_and_Their_Origins (February 15, 2021) 
18. Guerrero, L., Guàrdia M.D., Xicola J., Verbeke, W., Vanhonacker F., ZakowskaBiemans, S., Sajdakowska M., Sulmont-Rossé C., Issanchou S., Contel M., Scalvedi M. L., Granli B. S., \& Hersleth M. (2009). Consumer-driven definition of traditional food products and innovation in traditional foods. A qualitative cross-cultural study. Appetite, 52(2), 345-354. https://doi.org/10.1016/j.appet.2008.11.008

19. Guerrero, L., Claret, A., Verbeke, W., Enderli, G., Zakowska-Biemans, S., Vanhonacker, F., Issanchou, S., Sajdakowska, M., Granli, B. S., \& Scalvedi, L. (2010). Perception of traditional food products in six European regions using free word association. Food quality and preference, 21(2), 225-233. https://doi. org/10.1016/j.foodqual.2009.06.003

20. Lončarić, R., Rebekić, A., Zmaić, K., \& Sudarić, T. (2015). Consumer opinions and attitudes regarding Slavonia and Baranya traditional food products. Proceedings of the 50th Croatian and 10th International Agronomy Symposium (Pospišil, Milan, editor), University of Zagreb, Faculty of Agriculture, Zagreb. 148-152. Retrieved from: http://sa.agr.hr/pdf/2015/sa2015_proceedings.pdf

21. National Newspaper (2012). Croatian Parliament No 50/2012. Low on designations of origin, geographical indications and marks of traditional reputation of agricultural and food products. Retrieved from: https://narodne-novine.nn.hr/ clanci/sluzbeni/2012_05_50_1223.html (November 20, 2020)

22. National Newspaper (2015). Croatian Ministry of agriculture No 65/2015. Regulation on protected certificates of origin, geographical indications and guaranteed traditional specialties of agricultural and food products. Retrieved from: https://narodne-novine.nn.hr/clanci/sluzbeni/2015_06_65_1254.html (November 20, 2020)

23. Renko, S., \& Bučar, K. (2014). Sensing nostalgia through traditional food: an insight from Croatia. British Food Journal, 116(1), 1672-1691. https://doi.org/10.1108/ BFJ-02-2014-0089

24. Sajdakowska, M., \& Zakowska-Biemans, S. (2009). Polish consumer perception of traditional food based on the qualitative survey. Zywnosc-Nauka Technologia Jakosc, 16(3), 95-104. Retrieved from: https://www.researchgate.net/ publication/289132539_Polish_consumer_perception_of_traditional_food_based on_the_qualitative_survey

25. Slimani, N., Fahey, M., Welch, A.A., Wirfalt, E., Stripp, C., \& Bergstrom, E. (2002). Diversity of dietary patterns observed in the European Prospective Investigation into Cancer and Nutrition (EPIC) project. Public Health Nutrition, 5(6B). 13111328. https://doi.org/10.1079/PHN2002407

26. Trichopoulos, D., \& Lagiou, P. (2004). Mediterranean diet and overall mortality differences in the European Union. Public Health Nutrition, 7(7). 949-951. https:// doi.org/10.1079/phn2004559 
27. Trichopoulou, A., Soukara, S., \& Vasilopoulou, E. (2007). Traditional foods: a science and society Perspective. Trends in Food Science \& Technology, 18, 420 427. https://doi.org/10.1016/j.tifs.2007.03.007

28. Vandecandelaere, E., Teyssier, C., Barjolle, D., Jeanneaux, P., Fournier, S., \& Beucherie, O. (2021). Strengthening Sustainable Food Systems through Geographical Indications: Evidence from 9 Worldwide Case Studies. Journal of Sustainability Research 2(4), 1-37. https://doi.org/10.20900/jsr20200031

29. Vanhonacker, F., Lengard, V., Hersleth, M., \& Verbeke, W. (2010). Profiling European traditional food consumers. British food journal, 112 (8-9), 871-886. http://hdl.handle.net/1854/LU-1079078

30. Vanhonacker, F., Verbeke, W., Guerrero, L., Claret, A., Conte, M., Scalvedi, L., Zakowska-Biemans, S., Gutkowska, K., Sulmont-Rosse, C., \& Raude, J. (2010). How European Consumers Define the Concept of Traditional Food: Evidence from a Survey in Six Countries. Agribussiness, 26(4). 453-476. https://doi.org/10.1002/ agr.20241

31. van Ittersumm, K., Candel, M., \& Meulenberg, M. (2003). The influence of the image of a product's region of origin on product evaluation, Journal of Business Research, 56(3), 215-26. https://doi.org/10.1108/00070700810900585

32. Zmaić, K., Sudarić, T., Lončarić, R. (2014). Strengthening of local identity through evaluation of traditional regional products. Proceedings of 25th Scientific-Experts Congress on Agriculture and Food Industry / Yercan, M., Tepecik, M., Hatipoglu, A., Ozden, F., Tosun, D. Izmir, Turkey: Faculty of Agriculture, Ege University, 37-40 
